\title{
AC 2012-3223: INTEGRATION OF MECHANICAL AND AEROSPACE ENGINEERING PRELIMINARY DESIGN CAPSTONE COURSES
}

Prof. Brenda A. Haven, Embry-Riddle Aeronautical University, Prescott

Brenda Haven teaches thermodynamics and three jet propulsion courses at Embry-Riddle Aeronautical University (ERAU). Prior to coming to ERAU in 2008, Haven retired from the Air Force after 25 years working as an engineer in support of the F-15 fighter, advanced turbine engine research and development, and as a professor at the Air Force Academy.

\section{Prof. Michael Kenneth Fabian, Embry-Riddle Aeronautical University}

Michael Kenneth Fabian teaches thermodynamics, jet and rocket propulsion, and thermal power conversion courses at ERAU. He retired from the Air Force after 25 years and worked on advanced rocket engines, jet engines, and directed energy weapons. He was Program Manager for the first Lamilloy turbine, Branch Chief for world's first cryogenic full-flow rocket cycle, Deputy Director for Propulsion Directorate developing next generation jet engines with three flow paths instead of turbofan's two paths, and Faculty Advisor for ERAU Jet Dragster Project, Formula Research Club (March race car chassis), University Space Launch Initiative Club. He has a Ph.D. in aerospace engineering, University of Notre Dame, 1995, M.S. in aeronautics and sstronautics, University of Washington, 1989, (Oates Fellow), and a B.S. in aeronautical engineering, U.S. Air Force Academy, 1984. Email: fabianm1 @erau.edu.

\section{Mr. Alexander James Herring, General Electric - Aviation}

Alexander James Herring is a graduate of Embry-Riddle Aeronautical University's Prescott Campus with B.S. degrees in aerospace engineering and mechanical engineering. He is currently working for $\mathrm{GE}$ as a turbine engine component designer.

\section{Marissa Pinnola, Purdue University}

Marissa Pinnola graduated from Embry-Riddle Aeronautical University, Prescott, with a B.S. mechanical engineering in 2011. She is currently a student at Purdue University working towards her M.S. in mechanical engineering. Her current research focuses on forced response issues in high-speed axial compressors.

\section{Mr. Devan Berg, Embry-Riddle Aeronautical University}

Devan Berg is a recent mechanical engineering graduate of Embry-Riddle Aeronautical University. Currently, he is seeking full-time employment within the aerospace industry. Specifically, he would like to make contributions toward the advancement of the gas turbine engine. 


\title{
Integration of Mechanical and Aerospace Engineering Preliminary Design Capstone Courses
}

\begin{abstract}
This is one of two papers describing the propulsion capstone design experience at Embry-Riddle Aeronautical University in Prescott, Arizona. In 2007, we began accepting freshmen into our Mechanical Engineering (ME) program. In the 2010-2011 academic year, we offered for the first time the new ME capstone design courses with concentrations in either air-breathing propulsion or robotics. This paper describes the propulsion preliminary design course; a second paper will focus on the follow-on propulsion detail design course.
\end{abstract}

The first graduating class of ME majors included three students in the propulsion track. The mutual dependence of the new propulsion track and well-established aircraft preliminary design course under our Aerospace Engineering (AE) program made the integration of the ME propulsion and AE aircraft projects an attractive proposition. This paper discusses this teamed relationship and associated challenges, the design process, the various design phases throughout the semester, and some details of the resulting engine cycle and preliminary component designs for the inlet, nozzle, compressor, and turbine. In addition, the assessment of the course outcomes: demonstrating communication competence and proficiency in engineering design via a capstone experience, by members of our Industrial Advisory Board will be discussed.

As this was the first time the course was offered with a small group of students, this paper will also discuss the lessons learned as well as future adaptations that will be needed as the population of students within the propulsion track increases as the overall ME program grows.

\section{Introduction}

The Mechanical Engineering (ME) undergraduate program at Embry-Riddle Aeronautical University in Prescott, Arizona (ERAU) kicked off in the fall semester of 2007 and graduated its first students in the spring semester of 2011. The program requires the completion of a minimum of 129 credit hours of coursework distributed across the areas of Math and Science (33 hrs); Communications, Humanities, and Economics (21 hrs); Engineering Fundamentals (36 hrs); ME Specific (31 hrs); and Capstone Design ( $8 \mathrm{hrs})$.

Students in the ME program can choose to specialize in one of two tracks: Robotics or Propulsion. Each of the tracks contains four unique courses $(14 \mathrm{hrs})$, which includes the two capstone design courses: Preliminary Design and Detail Design. Although the ME program allows students to take any one of the four capstone design sequences offered by the Department of Aerospace and Mechanical Engineering, all of the ME Students in the 2010 - 2011 academic year opted for one of the two ME capstone design sequences. The Robotics track had 9 students; the Propulsion track had 3 students. This paper will discuss the Propulsion track courses, with special emphasis on the Propulsion Preliminary Design course offered for the first time in the history of the our campus. A subsequent paper will discuss the Propulsion Detail Design course $^{1}$. 


\section{Context}

The application of team-teaching was first introduced into the AE capstone design courses in the spring semester of 2003 with the addition of a communications instructor from the University's College of Arts and Sciences. ${ }^{2}$ The impetus for the team-teaching model was tied to students' perceived weakness in their communication skills as documented in alumni surveys. The intentional integration of engineering and communication paid large dividends in the preparation of students for employment immediately following graduation. ERAU AE alumni survey data in the area of skill preparation in technical writing shows an increase from 28.2 percent "Very Good" responses for the classes of 1999 through 2002 to 50 percent "Very Good" responses for the class of $2004 .^{3}$

The success of the team-teaching format encouraged the pursuit of other opportunities to enhance the learning environment in the capstone design courses. One such pursuit began in 2008 as plans for the ME Propulsion capstone design sequence were being developed. The basic idea was to combine the AE and ME preliminary design courses. In the AE Aircraft Preliminary Design course, students conceptualize a complete aircraft design. ${ }^{2}$ Prior to 2010, the AE design teams were limited to the selection and analysis of an existing propulsion system to propel their aircraft. With the new ME Propulsion Preliminary Design course, an aircraft "contractor" and engine "subcontractor" relationship could be formed. This mutual dependence of each of the design processes is intended to increase student learning by requiring the students to understand and work with engineers outside their discipline; and by further developing communication skills necessary to deal with shifting subsystem requirements and the real-world give-and-take at airframe/engine interfaces as each team's design evolves.

\section{ME Propulsion Track}

The ME Propulsion track design experience is different from other university propulsion design experiences. Of four universities investigated, all had their programs under their Aerospace Engineering major. The propulsion design tracks for the Air Force Academy ${ }^{4}$ and University of Kansas $^{5}$ are a two-course sequence with the first course focusing on aircraft design, and the second on the design of aircraft engine components. The propulsion design tracks for ERAU, in Daytona Beach, Florida ${ }^{6}$ and University of Cincinnati ${ }^{7}$ have a two- course propulsion design sequence. The first course focuses on engine layout, cycle optimization, and engine sizing to meet vehicle and mission requirements. The second course focuses on preliminary engine component design and integration. At ERAU in Prescott, the first of the two-course design experience results in an optimized engine cycle to meet aircraft mission performance requirements, and preliminary aerodynamic and structural design and integration of the major engine components. The second course entails hardware fabrication, and testing of a selected engine component or sub-component. The culmination of the students' design experience with hands-on fabrication and testing of engine hardware gives them a deep appreciation for the complexity of turbine engine components and the physical interactions between mechanical and aerodynamics forces within an engine.

The four courses comprising the ME Propulsion track are Turbine and Rocket Engines (AE 408), Advanced Propulsion (ME 417), Air-Breathing Propulsion Preliminary Design (AE 435), and 
Air-Breathing Propulsion Detail Design (AE 440). All courses within the track have a design focus and use as their basis texts written by Jack Mattingly, et.al. The two required texts are Elements of Propulsion: Gas Turbines and Rockets ${ }^{8}$; and Aircraft Engine Design ${ }^{9}$. Together, these texts provide a very good picture of the turbine engine design process from engine cycle analysis through component preliminary design.

In conjunction with the rigorous thermodynamic analyses, the texts are accompanied by basic cycle analysis and component design software tools the students will use in the follow-on courses. These software tools implement the thermodynamic analyses presented within the text and therefore the students can more easily understand the results the design tools are giving them. In all courses, students are required to complete hand-calculations so they understand what the tools are doing. The tools then allow them to easily iterate their design in order to meet specified or derived design constraints.

\section{Turbine and Rocket Engines Course}

The Turbine and Rocket Engines course is taken by ME students during the first semester of their junior year and by AE students in the first semester of their senior year. It provides the students with a strong background in turbine engine cycle analysis. This allows students to understand the connection between the fundamental turbine engine design parameters such as compressor pressure ratio and turbine inlet temperature, and the engine's performance in terms of specific thrust and thrust specific fuel consumption. It also delves into the analysis of engine off-design performance; that is, the performance of a given engine design at different flight conditions and throttle settings.

The strong emphasis on cycle analysis was done for a couple of reasons. First, it provides the AE student with skills and tools they can use to evaluate potential engine solutions supporting their aircraft capstone preliminary design course. The second is it provides the ME student with a level of intuition that enables them to effectively start the engine design iteration process given only broad air vehicle performance requirements.

\section{Advanced Propulsion Course}

The second Propulsion track course, Advanced Propulsion, is offered in the spring semester of the junior year. This course emphasizes turbine engine component design through the use of six component design projects, all tied to each other through cycle performance requirements and component design interfaces. These design projects have their foundation in the engine cycle selected based on a mission requirement. At the completion of this course, the students will have all the basic knowledge and tools they will need as they enter their capstone design courses the following semester as well as an appreciation of important component integration challenges.

The course begins by having the students perform a simple mission analysis that will provide the thrust and fuel consumption performance requirements of their engine design. They will tie their mission analysis to engine cycle analysis until they arrive at a suitable cycle that will satisfy the mission requirements and air vehicle constraints such as engine size limits. For the past two course offerings, the engine cycle has been limited to a non-afterburning turbojet engine capable 
of Mach 2+ flight with the only design variable being the compressor pressure ratio. This simplicity allows the students to apply what they've learned in the Turbine and Rocket Engines course to quickly converge on an engine cycle solution. The constraint of using a nonafterburning turbojet allowed more in-depth coverage of thermodynamic, aerodynamic, and structural consideration for the five primary engine components: supersonic inlet, compressor, combustor, turbine, and converging-diverging nozzle. Future classes will be modified slightly to allow coverage of afterburner design.

As the students progress through the course, they will be using design tools provided by the Elements of Propulsion: Gas Turbines and Rockets text as well as creating spreadsheets and Matlab programs that will allow them to easily iterate the mission and component analyses. The students will take this experience along with the tools they've developed into the next course: Air-Breathing Propulsion Preliminary Design.

\section{Air-Breathing Propulsion Preliminary Design Course}

The Air-Breathing Propulsion Preliminary Design Course is the first of two capstone design courses and is currently only offered in the fall semester. The course involves four distinct phases in the preliminary design process: mission specifications and design project planning; aircraft and engine preliminary sizing; engine cycle selection and integration; and engine component design. Each phase culminates in a group presentation; phases two through four require each $\mathrm{AE}$ and $\mathrm{ME}$ combined team to submit an integrated formal report. The presentations and reports are graded based on $25 \%$ for communication effectiveness and $75 \%$ for technical merit. In addition to the formal report, students are required to submit an individual abstract and peer evaluation.

The final presentation is evaluated by a panel of industry, government, and faculty experts. When possible, we have members of our Department's Industrial Advisory Board participate as panel members.

\section{Air-Breathing Propulsion Detail Design Course}

The Air-Breathing Propulsion Detail Design Course is offered in the spring semester immediately following the preliminary design course. It is configured to expand the students' experience into the realm of component design, hardware fabrication, and testing of a selected engine component or sub-component. In the spring semester of 2011, the students' efforts involved the fabrication of their first stage compressor blade design using rapid prototyping techniques, the development of an in-house aluminum casting apparatus to create an aluminum blade, analysis of the vibrational characteristics of the cast blade, and subsequent testing to verify the predicted blade response characteristics.

In the spring semester, the dates for all $\mathrm{ME}$ and $\mathrm{AE}$ preliminary and detail design final presentations coincide with the Department's annual Industrial Advisory Board meeting. This timing offers a great opportunity to assemble an evaluating panel comprised of Industrial Advisory Board members along with other available industry, government, or faculty experts. 


\section{AE and ME Preliminary Design Project Challenges}

The project selected for the first combined AE and ME preliminary design course was the design of a lightweight air-superiority area-defense aircraft. The requirements document given to both the $\mathrm{AE}$ and ME students is shown in Figure 1.

\section{Light-Weight Tactical Fighter}

\subsection{Statement of Need (SON)}

The U. S. Air Force and Navy have determined a need for a truly light-weight tactical fighter aircraft for air defense of land and sea resources. These manned aircraft will be deployed from land or ship and be capable of immediately engaging enemy fighter aircraft with radar and heat seeking missiles as well as a $20 \mathrm{~mm}$ gun. These aircraft will be extremely maneuverable and must be able to sustain a load factor of 9 Gs. The combat radius of these aircraft will be less than 200 NM but the mission profile will include a 10 minute Combat Air Patrol (CAP) and a three minute afterburner engagement with a total of one minute at high $G$ (9).

\subsection{Request for Proposal (RFP)}

This Request for Proposal addresses the development of a manned, light-weight tactical fighter capable of defending ground or sea-based resources within $200 \mathrm{NM}$ of the aircraft base.

\subsection{Vehicle Design Specifications/Requirements}

- Launched from land or ship.

- Maximum take-off gross weight of 25,000 lb.

- Sustained maneuver capability of $9 \mathrm{Gs}$ from sea level to $30,000 \mathrm{ft}$.

- Combat radius of $200 \mathrm{NM}$ with a three minute afterburner engagement which includes one minute at 9 Gs.

- Carry two radar and two heat seeking missiles as well as a $20 \mathrm{~mm}$ cannon.

- Capable of pursuing and engaging aircraft at Mach 0.8 or greater.

- Cockpit designed for high maneuvering at maximum pilot efficiency.

Figure 1. AE and ME Preliminary Design Requirements Document

The teaming arrangement combined an 8-person aircraft team and 3-person propulsion team. The propulsion team contained two students who were ME-only majors, the third was pursuing a double major in $\mathrm{AE}$ and ME. At the outset of the project, the authors knew there would be challenges along the way.

- What classroom configuration will allow the aircraft and propulsion teams to interact consistently and effectively throughout the project?

- How does a parallel propulsion system design effort "fit" into the existing well defined aircraft design methodology?

- How do the two teams integrate their efforts, especially early in the design process when there is very little information about the aircraft configuration?

- When is the propulsion cycle "frozen" so the students can begin component design efforts? 
- How can the design projects be scoped to allow small (ie., 3 students) or large (ie., greater than 6 students) propulsion groups to effectively contribute to the overall aircraft design?

Each of these five challenges will be discussed in the following sections: Classroom Configuration and Fitting into the Aircraft Design Process.

\section{Classroom Configuration}

The classroom configuration is perhaps the single most important element of the teaming relationship, especially for the first offering of the $\mathrm{AE}$ and $\mathrm{ME}$ combined project. The concept was to schedule both $\mathrm{AE}$ and ME courses in the same classroom at the same time. This allowed the teams to work together for a guaranteed two-hour block of time, three days per week. It also allowed students in both courses to be exposed to the guidance and design philosophy of two different engineering instructors and a single communications instructor.

The classroom used was a 36-computer design classroom with three attached breakout rooms that could be used for team meetings and practice presentations. In the AE program, it is not uncommon for almost every workstation to be occupied during the fall semester. Fall semester 2010 was no exception. There were a total of 33 AE students and 3 ME students. The seating arrangement deliberately put the $3 \mathrm{ME}$ students and their $8 \mathrm{AE}$ counterparts in 11 adjacent workstations. We also arranged to have 3 computers placed into one of the breakout rooms to allow the ME team to work while aircraft-specific lectures were taking place in the main classroom. This also gave the ME instructor and students the opportunity to discuss propulsionspecific material without disturbing the other 33 students.

We attribute the success of the combined project to this complete immersion into the overall design effort and the linking of the mutual success of the teams to a common grade on their presentations and reports. The details of individual versus group grading will be discussed later in the course assessment section of this paper. As we look to the future, it is anticipated that the class size of the ME propulsion design track will grow to the extent that placing both classes into a single classroom is not possible within the current College of Engineering facilities. In this case, the plan is to have the courses scheduled for the same time period, but in adjacent design classrooms. This will still facilitate communication between the two teams and provide the ability to practice and deliver combined project presentations during scheduled class time.

\section{Fitting into the Aircraft Design Process}

The aircraft design course follows a well defined design process that starts with a short, one-page aircraft requirements document as shown in Figure 1. It takes the students through four distinct design phases, culminating in a paper design that describes technical details pertaining to the aircraft dimensions; weight; fuselage configuration; cockpit layout; wing and empennage layout and design; design of the high lift devices and control surfaces; landing gear placement and design; static stability analysis; lift and drag characteristics; structural layout and materials selection; basic cost analysis; and the propulsion system configuration, performance, and integration. 
In the aircraft design process, the propulsion system selection usually takes approximately onethird of the way through the course. At this point, aircraft weight and drag characteristics have been refined to the point they can be used to get reasonable thrust estimates for all the mission legs. This is when the search for a suitable existing engine can begin in earnest. The integration of a propulsion team meant the activities associated with engine selection had to be moved earlier in the design process. In the following paragraphs, each of the four design phases will be discussed from the perspectives of both the Aircraft and Propulsion efforts.

\section{Phase I of the Design Process}

The AE Phase I efforts focus on team organization, roles and responsibilities, and understanding the aircraft and mission requirements. The tasks associated with the phases include articulating the need for the aircraft, researching existing aircraft the students predict will share similar characteristics with their design, and creating a Gantt chart containing a preliminary project timeline with dependencies of the activities associated with the student roles and responsibilities.

The ME team efforts paralleled the AE activities, but focused on extracting the requirements thought to effect the engine design, researching existing engines the students predict will share similar characteristics with their design, and creating a Gantt chart in coordination with the AE team. The two teams were thus linked in the research efforts and program planning very early in the design process. For the Phase I presentation, the two teams were integrated and received the same grade for the presentation.

\section{Phase II of the Design Process}

The AE Phase II efforts focused on defining the mission profile, estimating aircraft weight takeoff gross weight, and using the mission profile and aircraft performance requirements to construct a solution space via a constraint diagram. The constraint diagram, created by plotting the required Wing Loading versus Take-off Thrust-to-Weight for all anticipated critical aircraft flight conditions, provided initial sizing information for the aircraft wing area and engine. The aircraft weight estimation and constraint analysis were accomplished using information gathered from similar aircraft and the method presented in the aircraft design texts such as Airplane Design by Jan Roskam ${ }^{10}$, Aircraft Design: A Conceptual Approach by Daniel Raymer ${ }^{11}$ and Introduction to Aeronautics-A Design Perspective by Steven Brandt ${ }^{12}$.

The ME Phase II efforts again paralleled the AE efforts, except the approach was different. The ME team followed the constraint analysis process in the Aircraft Engine Design ${ }^{9}$ text. This involved using aircraft drag characteristics associated with "Current" and "Future" fighter models in the text. As can be seen in Figure 2, the two methods resulted in similar diagrams which increased student confidence in their results. With the aircraft design point and estimated aircraft take-off weight in hand, the ME students could begin engine cycle and mission analysis studies necessary to select and engine cycle and size it to meet the aircraft mission thrust and fuel consumption requirements for Phase III. 


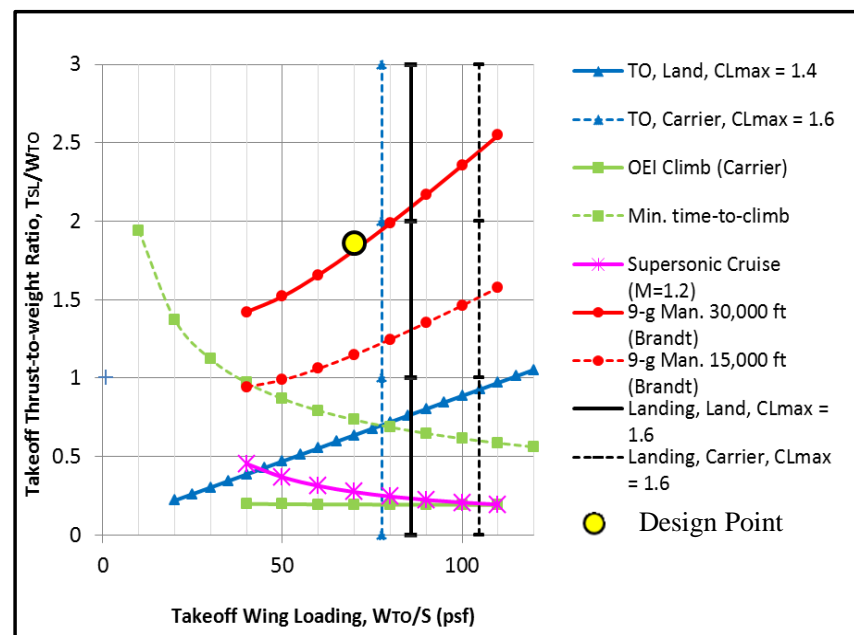

a) AE Constraint Analysis

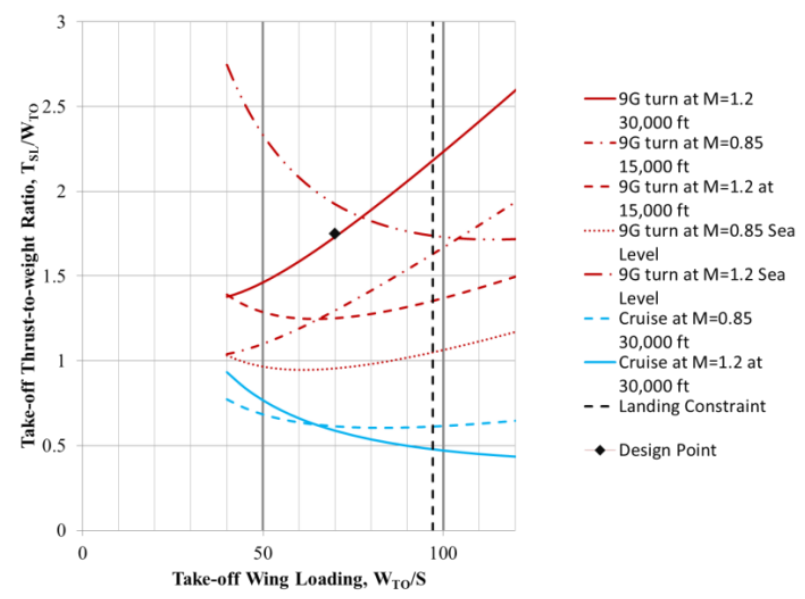

b) ME Constraint Analysis

Figure 2. Phase II Constraint Analyses Performed by AE and ME Design Teams

At the end of Phase II, the students again present their results as a combined team. They were also required to prepare an integrated formal report where both teams received the same grade.

\section{Phase III of the Design Process}

With the Phase II results in-hand, the AE Phase III efforts focused on refining the aircraft configuration and layout. Based on the roles and responsibilities defined in Phase I, students began the tasks of sizing the fuselage, wing airfoil selection and placement, empennage airfoil selection and placement, landing gear placement and sizing, static stability analysis, refinement of lift and drag characteristics based on wing and fuselage designs, and the integration and assessment of the engine being designed by the ME team.

In Phase III, the first order of business was to select the engine cycle. The combination of a 9-g turn requirement at 30,000 feet altitude and an aircraft maximum gross take-off weight of 25,000 pounds, led the students to select a dual-spool turbojet as their engine cycle. This minimized the engine diameter and engine weight for a given thrust requirement for aircraft packaging considerations. With the engine cycle in hand, the students sized with the engine to meet the 9-g turn requirement, created a mission profile and "flew" the engine through the mission to determine thrust required and fuel used at each mission stage. Based on similar engines, the engine weight and length were also estimated. The AE and ME team worked jointly to agree on preliminary inlet and nozzle placement. The sizing and location of each will be done in the next design phase. A picture of the aircraft at the conclusion of Phase III is shown in Figure 3, along with a specific excess power plot at the $9-\mathrm{g}$ turn at 30,000 feet altitude. This information was key to the AE team refinement of the aircraft mission profile since it shows the combinations of altitude and speed where the aircraft can meet the 9-g turn requirement. 


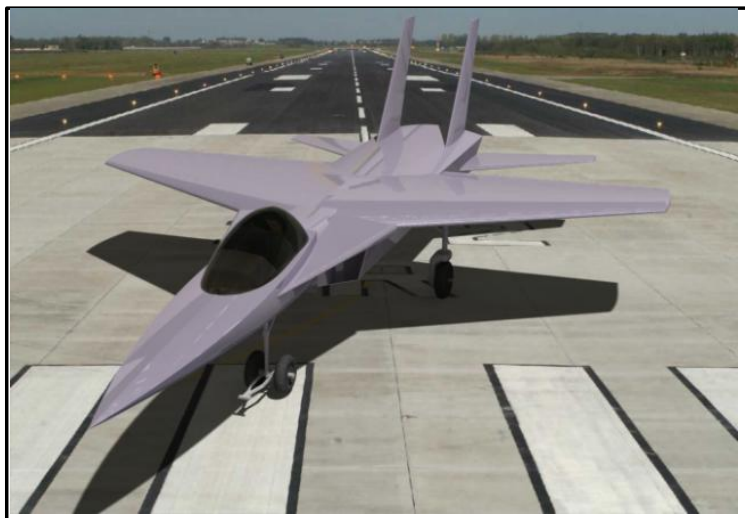

a) AE Phase III Aircraft Concept

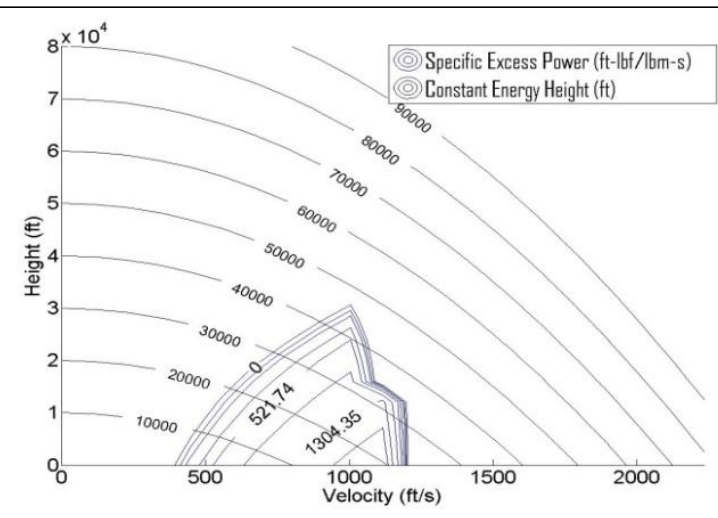

b) ME Specific Excess Power Available for 9-g turn

Figure 3. Phase III AE and ME Aircraft Design and Engine Performance

The presentation for Phase III was again integrated similar to the previous two phases with a common grade for the two teams. However, the divergence of the AE and ME design activities in Phase III prompted a change in the report format. The desire was to keep to a single report to describe the overall project, yet allow the ME students to present a more detailed account of their design process. It was decided to incorporate the "aircraft-relevant" propulsion material into the main body of the report and create an appendix for the propulsion system design detail. This did a couple of things. It kept the main report focused on the aircraft physical configuration and performance, and it allowed for the ME students' design results to be more accurately reported and assessed with the opportunity to assign independent grades for the two design efforts.

\section{Phase IV of the Design Process}

One of the most difficult questions to answer in this project was when to freeze the engine cycle characteristics so students could begin engine component design. Although the aircraft continues to undergo configuration changes in Phase IV that will affect drag and engine placement, the cycle was frozen at the end of Phase III. The interaction between the two teams lessened, but was still important due to the integration issues related to the inlet and nozzle. With a team of only three students, priority was given to the design of the inlet and nozzle, followed by the design of the compressor system and, and if there was time, the turbines.

In Phase IV the ME students divided the design tasks in the following manner: one person on the inlet and turbine section, one on the nozzle, and one on the low and high pressure compressor. The combustor and afterburner were not designed; however, their component lengths were estimated to give the aircraft team dimensional information for the entire engine. The final inlet and nozzle designs are shown as integrated in the final aircraft design along with an engine cut-away are shown in the Figure 4. These designs are the result of the students application of the design methodology covered in the Aircraft Engine Design ${ }^{9}$ text. 


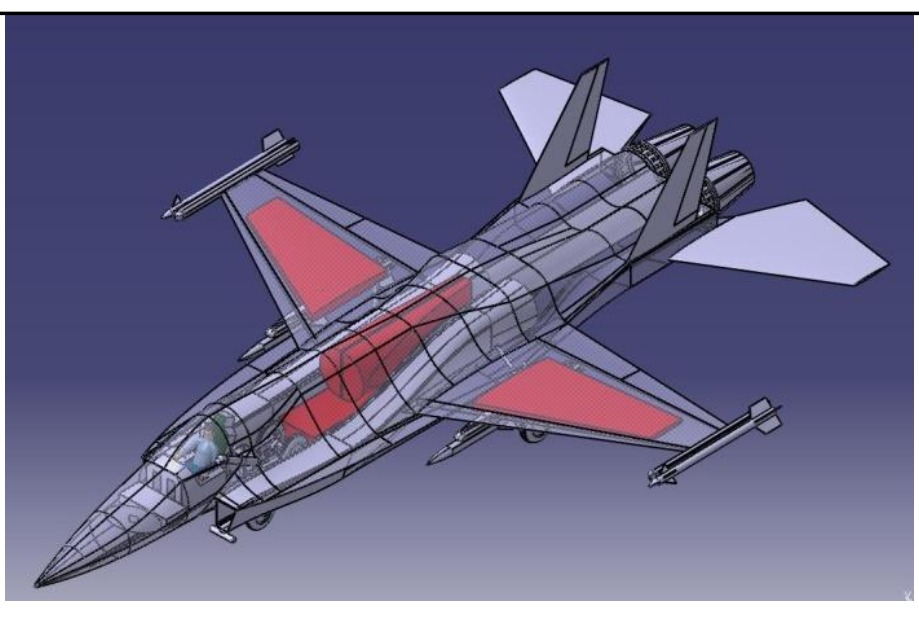

a) AE Aircraft with Inlet, Diffuser, and Nozzle

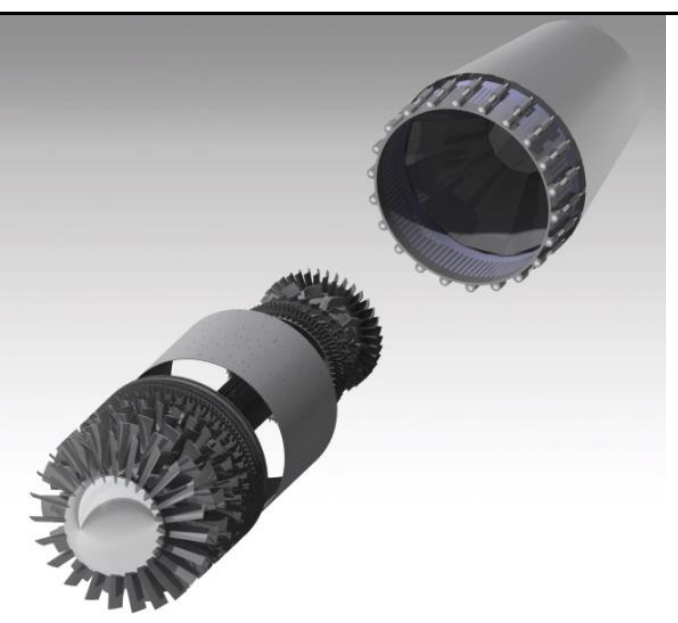

b) ME Turbomachinery and Nozzle

Figure 4. Phase IV Aircraft and Engine Design

\section{Course Assessment}

A fundamental challenge associated with group learning is to ensure accountability for individual contributions while promoting positive group interdependence. ${ }^{13}$ The first deliverable from each of the $\mathrm{AE}$ and $\mathrm{ME}$ groups was a Gantt chart showing the anticipated tasks throughout the semester and who was responsible for each task. This chart showed the group interdependence and individual responsibilities for each of the four phases of the design process and provided structure that clearly delineated the individual and group effort necessary to accomplish the design task. The Gantt chart was updated as needed throughout the semester and presented as an appendix in each phase design report.

To ensure individual accountability, 30 percent of the students' overall course grade was based on individual performance in the writing of report abstracts and an individual oral defense of their contribution to the overall project. The remaining 70 percent, three formal written reports and four presentations, was assigned group grades. Each report required an attributions table showing who wrote and edited each section. This attributions table enabled the grading instructor to differentiate individual contributions, as necessary, for the three report grades.

Peer evaluations were also an integral part of the course assessment program. One-half of the grade for each of the first three presentations was determined by peer input. Students used the same evaluation form as the faculty. The form, an example for the Phase II presentation is shown in Figure 5, gives clear criteria for what is expected for each presentation, which according to Barkley, et.al ${ }^{13}$, is crucial to good grading. Students also submitted peer evaluations, shown in Figure 6, prior to the end of Phases II through IV. The peer evaluation targets their assessment of their team members' contribution to the project. From an instructor's perspective, these peer assessments provide valuable input into the team dynamics based on activities that occur outside the formal class environment. 


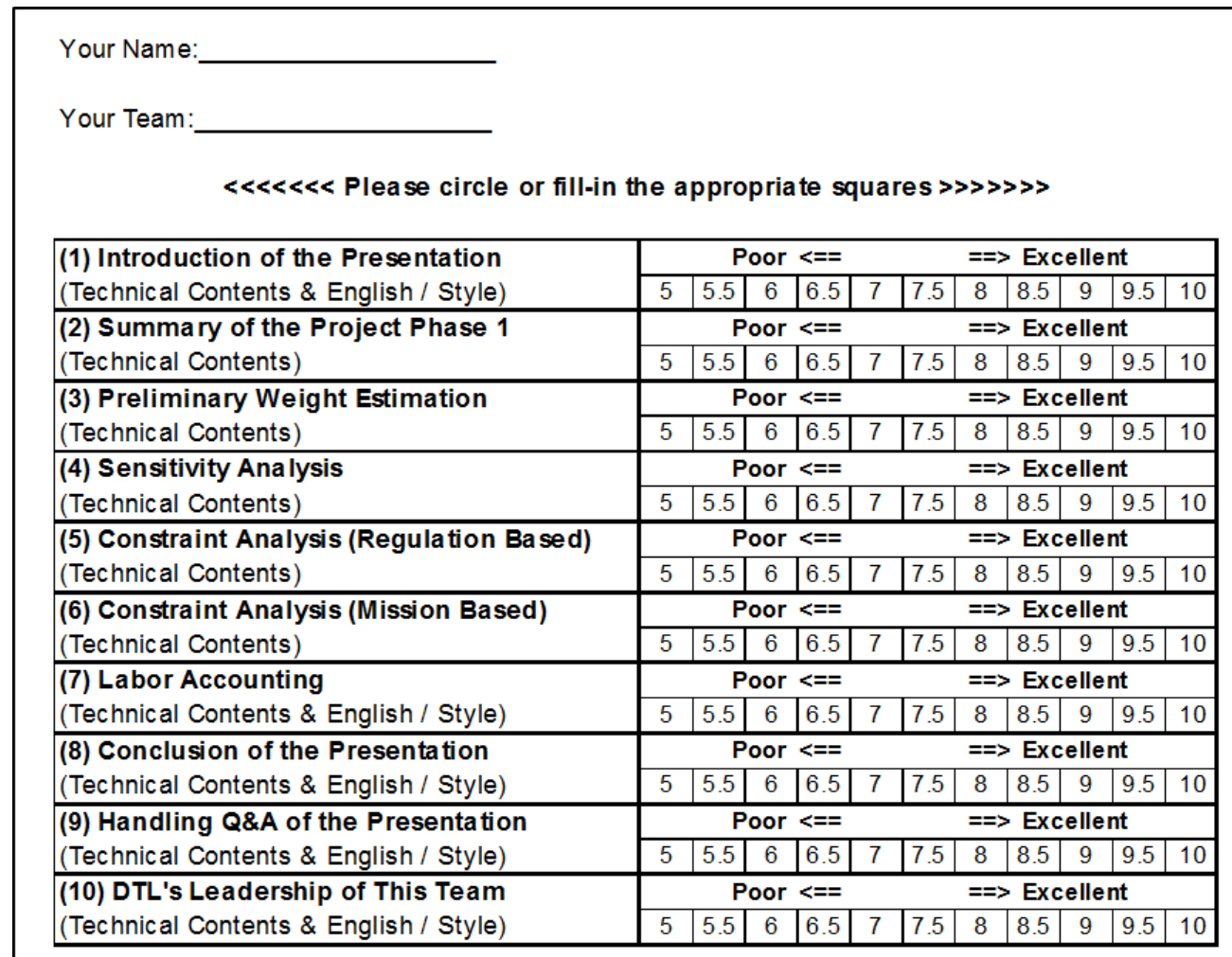

Your free comments (will be shared in the review session without names specified)

Figure 5. Phase II Presentation Evaluation Form

\begin{tabular}{|l|c|c|c|c|c|c|c|c|c|c|c|l|}
\hline Team Member 1 & 5 & 5.5 & 6 & 6.5 & 7 & 7.5 & 8 & 8.5 & 9 & 9.5 & 10 & Attendance at team activities \\
\hline Name: & 5 & 5.5 & 6 & 6.5 & 7 & 7.5 & 8 & 8.5 & 9 & 9.5 & 10 & Qual ity of work (output of tasks) \\
\cline { 2 - 10 } & 5 & 5.5 & 6 & 6.5 & 7 & 7.5 & 8 & 8.5 & 9 & 9.5 & 10 & Participation to the team discussions \\
\cline { 2 - 9 } & 5 & 5.5 & 6 & 6.5 & 7 & 7.5 & 8 & 8.5 & 9 & 9.5 & 10 & Attitude toward the successful team work \\
\cline { 2 - 9 } & 5 & 5.5 & 6 & 6.5 & 7 & 7.5 & 8 & 8.5 & 9 & 9.5 & 10 & Overall contribution to the team \\
\hline
\end{tabular}

Figure 6. Student Peer Evaluation Form

With the exception of the individual oral defense, all presentations, abstracts, and reports also contained a communication evaluation component. Twenty-five percent of the grade was based on effective communicate and was assigned by a University College of Arts and Sciences professor assisting with the course.

The Propulsion Preliminary Design Course targets four student outcomes:

1. Graduating students will have experienced a core of humanities, social sciences, and communications and demonstrate the use of this core to enhance the technical content of their engineering curriculum.

2. Engineering students graduating from our programs will demonstrate proficiency in core topics in their program.

3. All engineering students will be proficient in engineering design.

4. All engineering students will demonstrate design competence through a major design (capstone) experience. 
Evaluating students against these four outcomes during Phases I through III was done using a Presentation Evaluation Form such as that shown in Figure 5 along with a similar approach for the three formal reports. This enabled mapping of student performance throughout the semester back to these four outcomes.

One of the strengths of the program is having engineers from industry evaluate the final, Phase IV, presentation for all capstone design courses. They provide their assessment of the student's performance in the areas of Technical Accuracy and Completeness, Organization and Development of the presentation material, Neatness and Professionalism, and use of Visual Aids and Presentation Skills. These areas are rated by the panel on a scale of 1 to 5, 5 being the highest level of performance. The results of the six-member are given in Table 1 below:

\begin{tabular}{|l|c|}
\hline \multicolumn{2}{|c|}{ Table 1. Phase IV Presentation Assessment } \\
\begin{tabular}{|l|c|}
\hline \multicolumn{1}{|c|}{} & Average Score out of 5 \\
\cline { 2 - 3 } & Technical Accuracy and \\
Completeness & 4.4 \\
\hline Organization and Development & 4.4 \\
\hline Neatness and Professionalism & 4.8 \\
\hline Visual Aids and Presentation skills & 4.4 \\
\hline
\end{tabular} \\
\hline
\end{tabular}

This panel's scores indicate a balance in terms of their technical competence in the area of design and their ability to effectively communicate technical results. It also reveals the success the students had at weaving design information from two disciplines into a single well-integrated story.

In addition to the quantitative scoring of the students' performance, there was observed growth by students in the area of communication and conflict resolution. At the start of the semester, there was a very apparent discomfort on the part of the propulsion team members in finding meaningful "things" to do and understanding where they fit into the aircraft design process. The intentional vagueness on the part of the instructors relative to report and presentation formats and expectation caused the students to flounder initially, but in the end resulted in a much more cohesive product because the two teams had negotiate and work through different integration approaches. Communication difficulties were compounded by the addition of three students who had different academic experiences due to their different degree program.

\section{Lessons Learned, Future Adaptations, and Summary}

The overall opinion of the combined design project by the University and College of Engineering leadership, engineering design faculty, and participating students was that the project was an overwhelming success. From a faculty perspective, it was great to have a group of students in the first offering of the course who excelled in an environment that demanded flexibility and a great deal of initiative. 
In an exit interview with the three ME students, the thing that frustrated them the most was the lack of guidance, especially early in the course. They felt there was a significant amount of wasted time during Phase I of the process, and if they knew more of what was coming, they could have begun research and other preparation activities that would have allowed them time at the end of the course to perform more design work. They also thought additional guidance for the written reports would have been helpful. This was addressed somewhat during the Phase IV component design effort when the ME report became more of a "stand-alone" document as well as appendix to the AE report. The addition of guidance documents became the most significant area of course revision for the second offering of the course in the fall semester of 2011.

Another area was the importance of communication among and between the groups. Having a common class period greatly facilitated the interaction of the AE and ME teams as well as faculty. The common period simplified the delivery of lectures by the communications faculty and enabled joint team presentations throughout the semester. Yet there were some drawbacks. It was difficult to have group discussions and work sessions in the classroom when the other class had other lectures or activities going on. With only three students, we were able to configure one of the breakout rooms with three computers so they could discuss the project amongst themselves as well as do their individual design work while other AE business was being taken care of in the primary classroom. This approach worked well for a small group of ME students, however, in the fall semester of 2011, this was not feasible due to an increases ME enrollment to 11 students. In the fall semester 2011, the two courses were staggered by one hour. That meant the students in both $\mathrm{AE}$ and ME had one hour three days per week to work directly with their respective instructor to answer questions and deliver course material of interest only to their class. There was also one hour three days per week where the students were in the same classroom. For the most part, this process worked well by allowing consistent team interaction and joint participation in presentations and communications faculty lectures. Although this arrangement had its positive aspects, students did comment that sometimes the instructors in the two courses where giving slightly different guidance to the different classes.

As we look forward to the future of $\mathrm{AE}$ and $\mathrm{ME}$ collaboration in the preliminary design courses, the issue of how to accommodate a variety of group sizes is important. As we went from 3 students to 11 students in one year, we learned important information about what we can expect students to be able to accomplish, and what a "good" size is for a typical project. Based on fall 2011, a group of 5 or 6 is excellent for performing all Phase I through III work by dividing up the various tasks. In Phase IV, component design, a minimum of 5 students is needed to be able to satisfactorily design multiple compression and turbine sections, a combustor, afterburner, inlet and nozzle. With the addition of 1 to 3 additional students on a team, the students will be able to delve into design work associated with mechanical systems such as shaft, bearing, and casing design, variable stator designs, more in-depth structural analysis of rotating components and secondary flow associated with turbine cooling. With upward of 10 or more students, the projects can entail competing aircraft and engine designs as was done in the fall of 2011.

The teamed approach for the AE and ME capstone preliminary design courses was very successful in the fall of 2010 as evidence by the high marks of the evaluating panel. With a few modifications based on these lessons learned, the fall 2011 offering, which involved two competing combined teams, was even more successful. The final design products involving the 
overall engine layout and individual component design detail were much better integrated due to all the major engine components being designed simultaneously. A sentiment on the students' end-of-course evaluation gives insight into how the students felt about the experience: "Overall the integration between the two teams was a great learning experience. Having a project designed and setup as if in industry really does provide an advantage over other prelim design projects." There are still things to work on, but the overall teaming concept has proven to be rewarding for both students and faculty and worth continuing.

\section{Acknowledgements}

The authors wish to thank Prof. Jeff Ashworth and his Aircraft Preliminary Design course students Justin Gross, James Cameron, Marco Ferraris, Kevin Hensberry, Steven Kamada, Zachary Leitch, Benjamin Moore, and Alexander Morgan for their aircraft performance information and CATIA drawings used in this paper.

\section{References}

${ }^{1}$ Fabian, Michael K.; Brenda Haven; Devan Berg; Alexander Herring; and Marissa Pinnola. "Implementation of a New Mechanical Engineering Propulsion Detail Design Capstone Course" Proceedings of the 2012 ASEE Annual Conference, San Antonio, TX: ASEE, 2012.

${ }^{2}$ Helbling, Jim; David Lanning, Ron Madler, Angela Beck, and Patric McElwain. "Integrating Communications into Team-Taught Senior Design Courses" Proceedings of the 2005 American Society for Engineering Education Annual Conference and Exposition, Washington DC: ASEE, 2005.

${ }^{3}$ Helbling, James. "Integrating Design Application and Communication Skills Into Senior Design Courses" Proceedings of the 2009 American Society for Engineering Education Pacific Southwest Regional Conference, San Diego CA: ASEE, 2009.

4"USAFA Curriculum Home." Web. 13 Mar. 2012. <http://www.usafa.edu/df/dfr/curriculum/curriculum.cfm?catname=dfr2>.

5"Aerospace Engineering." University of Kansas School of Engineering:. Web. 13 Mar. 2012. <http://ae.engr.ku.edu/undergraduate/courses.html>.

6"Current Embry-Riddle Catalogs for 2011-12." 2009-2010 Course Catalogs for Embry-Riddle Aeronautical University -. Web. 13 Mar. 2012. <http://www.erau.edu/degrees/catalog/index.html>.

7"Courses, University of Cincinnati." CEAS, Aero, University of Cincinnati. Web. 13 Mar. 2012. <http://aerospace.ceas.uc.edu/undergraduate/undergradAse/undergrad_courses.html>.

${ }^{8}$ Mattingly, Jack D. (2006). Elements of Propulsion Gas Turbines and Rockets. Reston, Virgina: AIAA Education Series.

${ }^{9}$ Mattingly, Jack D; William H. Heiser, David T. Pratt. (2002). Aircraft Engine Design, $2^{\text {nd }}$ Edition. Reston, Virgina: AIAA Education Series.

${ }^{10}$ Roskam, Jan (1985). Airplane Design, Ottawa, Kan. : Roskam Aviation and Engineering Corp., 1985. 
${ }^{11}$ Raymer, Daniel (2006). Aircraft Design: A Conceptual Approach, $4{ }^{\text {th }}$ Edition. Reston, Virgina: AIAA Education Series.

${ }^{12}$ Brandt, Steven A.; Randall J. Stiles; John J. Bertin; Ray Whitford (2004). Introduction to Aeronautics-A Design Perspective, $2^{\text {nd }}$ Edition. Reston, Virgina: AIAA Education Series.

${ }^{13}$ Barkley, E. F., Cross, K. Patricia. (2005). Collaborative learning techniques: a handbook for college faculty. San Francisco: Jossey-Bass. 